\title{
PENGARUH INFLASI, SUKU BUNGA AS, HARGA EMAS, HARGA MINYAK BUMI, INFLASI AS DAN KURS RUPIAH TERHADAP INDEKS SEKTORAL DI INDONESIA
}

\author{
Sylvin Antonius \\ Program Studi Magister Manajement Universitas Tarumanagara \\ Sylvinantonius@gmail.com
}

\begin{abstract}
This thesis created to study the effect from each macro variable from Dow Jones Index, US Interest Rate, Price of Gold, Price of Oil, US Inflation and Rupiah Exchange Rate to Sectoral Indicies and help investors to make a better decision for investors in investing. The timeline of the data for this study will start from 2014 to 2016 where some changes will be seen in US Interest Rate. The analysis method that will be used in this study will be regression where a different assumption can be made even though a lot of previous study results in significancy with IHSG. Finally, not all data show significancy when compared to each sector from Sectoral Indicies. This fact can be checked from the significance from doing T test from Eviews9. Assumption that can be seen here is that macro data such as Dow Jones Index got high significancy with Sectoral Indicies while others are lower.
\end{abstract}

Keywords: Dow Jones Index,Gold Price, Oil Price, Inflation, Interest Rate, Rupiah Exchange Rate

\section{PENDAHULUAN}

Berdasarkan Buku Panduan Indeks Harga Saham Bursa Efek Indonesia (2010), IHSG merupakan indeks yang menggunakan semua emiten yang tercatat sebagai komponen perhitungan indeks. IHSG pertama kali diperkenalkan pada tanggal 1 April 1983 sebagai indicator pergerakkan harga saham yang tercatat di bursa. Disaat kondisi sekarang ini, dapat dilihat banyak pergerakkan saham yang tidak sesuai dengan kondisi keuangan perusahaan. Oleh sebab itu, banyak analis dan investor mengalami kerugian karena analisa yang tidak tepat. Hal ini terjadi karena ada faktor lain yang mempengaruhi harga saham.

Faktor yang dapat memengaruhi indeks saham, antara lain perubahan suku bunga, nilai tukar rupiah, inflasi, harga emas, indeks global, tingkat harga energi dunia, kestabilan politik suatu negara dan lain-lain. Moradoglu, et al. (2000), dikemukakan bahwa penelitian tentang perilaku harga saham telah banyak dilakukan, terutama dalam kaitannya dengan variabel makroekonomi, diantaranya Chen et al. (1986), dan Fama (1981). Harga minyak juga menjadi salah satu faktor penting karena perubahan harga minyak tentunya akan mengakibatkan fluktuasi pada inflasi dari sektor energy yang akan berpengaruh ke inflasi dan juga ke kinerja perusahaan. Keterkaitan antar bursa saham Indonesia dengan bursa saham luar negeri dapat dilihat ketika terjadi krisis keuangan global pada tahun 2008. Menurut Hirt dan Block (1993: 86), arah pergerakkan dari seluruh indeks memiliki hubungan yang erat akan tetapi bukan berarti mereka akan bergerak bersamaan.

Menurut Fabozzi dan Franco (1996), kurs mata uang didefinisikan sebagai jumlah nilai sebuah mata uang yang dapat ditukarkan untuk mata uang lain. Ajayi dan Mougoue (1996) juga menggunakan variabel makroekonomi nilai tukar dan harga saham. Hasil penelitian mereka menunjukkan hubungan yang signifikan antara nilai tukar dan harga saham (pasar modal dan pasar uang). Penulis hanya mengambil rentang waktu selama 3 tahun yaitu dari tahun 2014-2016 karena dengan membatasi rentang waktu penelitian maka hasil penelitian akan lebih mempresentasikan hubungan antara indeks dengan kondisi ekonomi macro pada saat ada perubahan suku bunga dari Amerika Serikat dan perubahan harga emas maupun minyak yang cukup volatile. 


\section{POKOK MASALAH}

1. Banyak pergerakkan indeks yang dipengaruhi oleh factor macro.

2. Sulitnya mencari peluang investasi dan melihat kesempatan untuk berinvestasi.

3. Sulitnya meramalkan kondisi masa depan untuk memulai investasi.

\section{TUJUAN PENELITIAN}

1. Untuk menguji Pengaruh Dow Jones Index, terhadap Indeks Sektoral.

2. Untuk menguji Pengaruh Suku Bunga terhadap Indeks Sektoral.

3. Untuk menguji Pengaruh Harga Emas terhadap Indeks Sektoral.

4. Untuk menguji Pengaruh Harga Minyak Bumi terhadap Indeks Sektoral.

5. Untuk menguji Pengaruh Inflasi terhadap Indeks Sektoral.

6. Untuk menguji Pengaruh Kurs Rupiah terhadap Indeks Sektoral.

7. Untuk menguji Pengaruh Dow Jones Index, Suku Bunga AS, Harga Emas , Harga Minyak Bumi, Inflasi AS dan Kurs Rupiah secara bersama-sama terhadap Indeks Sektoral.

\section{TINJAUAN PUSTAKA}

\section{Indeks di Bursa Efek Indonesia}

Indeks harga saham adalah cerminan pergerakkan harga saham yang dipengaruhi oleh meningkatnya aktivitas perdagangan (Buku Panduan Indeks Harga Saham Bursa Efek Indonesia, 2010). Perlu diketahui beberapa jenis indeks yang ada di BEI yaitu:

\section{Indeks Harga Saham Gabungan (IHSG)}

Indeks yang menggunakan semua emiten yang tercatat sebagai komponen perhitungan indeks (Buku Panduan Indeks Harga Saham Bursa Efek Indonesia, 2010).

\section{Indeks Harga Saham Sektoral (Sector Stock Price Index)}

Indeks yang merupakan sub indeks dari IHSG (Buku Panduan Indeks Harga Saham Bursa Efek Indonesia, 2010).

\section{Dow Jones Index}

Indeks ini merepresentasikan dari kegiatan perekonomian dari 30 perusahaan terbesar di AS. Indeks ini meliputi jutaan orang dan trilliunan dolar AS yang dapat merepresentasikan system ekonomi (Sergey Khrystenko, 2007).

\section{Suku Bunga}

Suku Bunga sering juga disebut dengan discount rate dan opportunity cost rate (Canada, Sullivan, and White, 1996). Dalam penelitian ini, suku bunga yang dikaji adalah suku bunga Amerika Serikat.

\section{Harga Emas}

Emas merupakan salah satu komoditi yang berguna sebagai investasi karena harganya yang terus naik dengan peningkatan laju inflasi. Investor umumnya membeli emas sebagai perlindungan asset atau safe haven (Michael Maloney, 2011).

\section{Harga Minyak Bumi}

Minyak bumi merupakan komoditi strategis yang diperlukan oleh seluruh negara. Ketergantungan manusia terhadap BBM semakin tinggi sehingga kebijakan penetapan harganya menjadi sangat tinggi (Nugrahanti Asri, 2010).

\section{Inflasi}

Inflasi didefinisikan sebagai kecenderungan dari kenaikan harga barang secara umum dan terus menerus (Boediono, 2001).

\section{Kurs}


Menurut (Siamat, 2001), Kurs atau nilai tukar (kurs) adalah harga suatu mata uang dinyatakan dalam mata uang lain. Nilai tukar yang berdasarkan pada kekuatan pasar akan selalu berubah disetiap kali nilai-nilai salah satu dari dua komponen mata uang berubah.

\section{METODE PENELITIAN}

\section{A. Desain Penelitian}

Penelitian yang dilakukan termasuk jenis penelitian penjelasan yang mengukapkan data untuk menjelaskan hubungan-hubungan antara variable. Data yang digunakan adalah data indeks berbagai sector dari IHSG, kurs rupiah terhadap dollar AS, inflasi rupiah, tingkat suku bunga AS, Dowjones, Emas dan harga minyak bumi dunia dengan periode 2014 -2016.

B. Sumber dan Pengumpulan Data

Pengumpulan data yang digunakan dalam penelitian ini adalah dengan dokumentasi yang dilakukan dengan browsing dan mengunduh data pada websitewebsite:

1. www.investing.com

2. www.idx.co.id

3. www.sahamok.com

C. Variable Penelitian dan Operasionalisasi Variabel

\section{Variabel Dependen}

Variabel dependen dalam penelitian ini adalah Indeks sektoral dari IHSG. Dalam penelitian ini, angka yang dipakai adalah harga penutupan (closing price) yang dipublikasikan pada periode 2014 - 2016.

\section{Variabel Indenpenden}

Variable indenpenden merupakan variable yang dapat menjelaskan variable dependen. Adapun Variabel indenpenden yang ada pada diatas antara lain:

a. Dow Jones Index

Kecenderungan perubahan pada indeks ini dan volatilitasnya dapat mempengaruhi indeks lain secara tidak langsung.

b. Suku Bunga AS

Kenaikkan suku bunga AS akan mengakibatkan bunga pinjaman hutang dalam bentuk dollar AS naik dan menyebabkan perlemahan dalam bisnis yang hutangnya ataupun transaksinya dalam bentuk dolar AS.

c. Harga Emas

Pada saat investor mulai tidak yakin dengan stabilitas kondisi ekonomi, investor cenderung memindahkan uang menjadi emas.

d. Harga Minyak Bumi

Perubahan harga minyak bumi pada umumnya akan menaikkan cost secara overall dan berpengaruh terhadap ekonomi dan perkembangan bisnis.

e. Inflasi

Inflasi adalah kenaikkan harga barang yang berubah-ubah seiring waktu, tingkat pertumbuhan ekonomi dan kondisi pasar.

\section{f. Kurs Rupiah}

Kurs rupiah adalah perbandingan mata uang antara rupiah dengan dolar AS.

menjadi emas.

D. Metode Analisis

\section{Uji Asumsi Klasik}

Pengujian asumsi klasik yang akan digunakan dalam penelitian ini adalah:

a. Uji Autokorelasi 
Uji autokorelasi bertujuan menguji apakah dalam model regresi ada korelasi antara kesalahan pengganggu periode $\mathrm{t}$ dengan $\mathrm{t}-1$ atau periode sebelumnya.

b. Uji Heteroskedastisitas

Heteroskedastisitas adalah ketidaksamaan variasi variable dan kesalahan yang terjadi yang memperlihatkan hubungan sistematis sesuai dengan besarnya satu atau lebih variable bebas sehingga tidak ada error yang random.

\section{Analisis Regresis Linier Berganda}

Analisis regresi adalah metode untuk menentukan hubungan sebab akibat antara satu variable dengan yang lain.

Menurut Ghozali (2011) persamaan regresi linear berganda dapat dinyatakan sebagai:

$\mathrm{Y}=\alpha+\beta 1 \mathrm{X} 1+\beta 2 \mathrm{X} 2+\beta 3 \mathrm{X} 3+\beta 4 \mathrm{X} 4+\beta 5 \mathrm{X} 5+\beta 6 \mathrm{X} 6+\varepsilon$

Y merupakan Indeks sectoral IHSG, X1 merupakan Indeks Dow Jones, X2 merupakan Suku Bunga AS, X3 merupakan harga emas, X4 merupakan Harga Minyak Bumi, X5 adalah Inflasi Amerika, X6 adalah Kurs rupiah terhadap dolar AS, $\beta 1, . . \beta$ ? Merupakan Koefisien Regresi, $\alpha$ merupakan Konstanta dan $\varepsilon$ merupakan Standard Error.

\section{E. Hipotesis Statistik dan Pengujiannya}

\section{Uji Parsial (Uji statistic t)}

Uji t dilakukan pada tingkat keyakinan 95\% dengan ketentuan:

$\mathrm{H} 0$ : Apabila p-value $>0,05$ maka $\mathrm{H} 0$ diterima

Ha : Apabila p-value >0,05 maka Ha diterima (Ghozali, 2011:178)

\section{Uji F}

Uji $\mathrm{F}$ dimaksudkan untuk menguji model regresi atas mengaruh seluruh variable indenpenden secara simultan terhadap dependen. Nilai signifikansi kurang dari 0,05 berarti variable indenpenden dapat digunakan untuk memprediksi variable dependen.

\section{Koefisien Determinasi $\left(\mathbf{R}^{2}\right)$}

Nilai koefisien determinasi adalah antara 0 dan 1 . Nilai yang mendekati 1 berarti informasi untuk memprediksi variable dependen sudah hampir diketahui secara keseluruhan.

\section{ANALISIS DAN PEMBAHASAN}

\section{A. Deskripsi Statistik}

Deskripsi Statistik terdiri dari variable indenpenden : Dow Jones Index, suku bunga efektif Amerika, harga emas, harga minyak bumi, inflasi AS dan Kurs Rupiah terhadap Dolar AS. Dengan variable dependen yaitu Agriculture, Basic Industry, Consumer, Finance, Infrastructure, Manufacture, Mining, Misc Industry, Property dan Trade dengan jumlah observasi 36.

\section{B. Analisis Data}

\section{Uji Autokorelasi}

Model regresi yang baik adalah model yang tidak memiliki auto korelasi. Jika hasil uji autokorelasi diatas 0,05 maka berarti tidak terdapat Autokorelasi. Seluruh data penelitian telah memenuhi persyaratan tersebut maka dapat disimpulkan bahwa tidak ada Autokorelasi dari seluruh data diatas.

\section{Uji Heteroskedastisitas}

Jika hasil uji heteroskedastisitas lebih besar dari 0,05 maka tidak terdapat Heterokedastisitas dan itu merupakan model regresi yang baik. Seluruh data penelitian sudah memenuhi persyaratan tersebut. Dengan itu, hal ini membuktikan bahwa data ini sudah layak dipakai untuk penelitian ini. 


\section{Analisis Regresi Berganda}

Agriculture: $\quad 0,09$ (Dow Jones Index) + (-1.084,506) (Effective Fed Funds

Rate $)+(-0,108)($ Gold $)+(-4,552)($ Oil $)+9.658,319$ (Us Inflation $)+(-0,295)($ USDIDR $)+4862,455$

Basic Industry: $\quad$ 0,035 (Dow Jones Index) + 95,548 (Effective Fed Funds Rate) $+\quad(-0,046)($ Gold $)+0,698($ Oil $)+(-5.290,553)(U s$ Inflation $)+\quad(-0,067)($ USDIDR $)+717,783$

Consumer: 0,083 (Dow Jones Index) + 24,885 (Effective Fed Funds Rate) + 0,966 $($ Gold $)+(-5,954)($ Oil $)+4.720,624$ (Us Inflation $)+(-0,037)$ $($ USDIDR $)+397,192$

Finance: $\quad$ 0,048 (Dow Jones Index) + (-117,344) (Effective Fed Funds Rate) + $0,119($ Gold $)+(-2,512)($ Oil $)+2.215,295($ Us Inflation $)+(-0,047)$ (USDIDR) + 488,898

Infrastructure: $\quad 0,083$ (Dow Jones Index) $+24,885$ (Effective Fed Funds Rate) $+0,966($ Gold $)+(-5,954)($ Oil $)+4.720,624($ Us Inflation $)+(-$ $0,037)($ USDIDR) $+397,192$

Manufacture: $\quad$ 0,06 (Dow Jones Index) + 13,19 (Effective Fed Funds Rate) + $0,403($ Gold $)+(-2,35)($ Oil $)+(-629,045)($ Us Inflation $)+(-$ $0,09)$ (USDIDR) + 1.043,66

Mining: $\quad 0,175$ (Dow Jones Index) + (-220,163) (Effective Fed Funds Rate) + $0,306($ Gold $)+8,201($ Oil $)+21.981,956$ (Us Inflation $)+(-0,063)$ (USDIDR) - 1.845,407

Misc Industry: $\quad$ 0,068 (Dow Jones Index) + (-193,109) (Effective Fed Funds Rate $)+0,532($ Gold $)+(-3,038)($ Oil $)+4.193,743$ (Us Inflation $)+(-0,129)($ USDIDR $)+1278,557$

Property: 0,0475 (Dow Jones Index) + (-127,25) (Effective Fed Funds Rate) + $0,199($ Gold $)+(-2,281)($ Oil $)+340,844$ (Us Inflation $)+(-0,023)$ (USDIDR) - 111,881

Trade: $\quad 0,02$ (Dow Jones Index) + (-14,714) (Effective Fed Funds Rate) + $0,173($ Gold $)+(-0,741)($ Oil $)+1.271,671($ Us Inflation $)+(-0,006)$ (USDIDR)

\section{Uji Hipotesa Penelitian}

\subsection{Uji T}

Pengujian hipotesa sesuai tabel terhadap beberapa hipotesis yang telah dirumuskan sebelumnya yang terdiri dari 6 hipotesis sebagai berikut: Variabel indenpenden Dow Jones Index menunjukkan bahwa Dow Jones Index berpengaruh signifikan terhadap sebagian besar Indeks Sektoral di Indonesia kecuali terhadap sektor Trade. Variabel indenpenden Suku bunga efektif AS menunjukkan bahwa suku bunga efektif AS tidak berpengaruh signifikan terhadap sebagian besar Indeks Sektoral di Indonesia kecuali terhadap sektor Agriculture dan Property. Variabel indenpenden Harga emas menunjukkan bahwa Harga emas memiliki tidak memiliki pengaruh secara keseluruhan terhadap Indeks Sektoral tetapi berpengaruh terhadap sektor-sektor tertentu saja seperti sektor Consumer, Manufacture, Property dan Misc Industry. Variabel indenpenden Harga minyak bumi menunjukkan bahwa Harga minyak bumi berpengaruh terhadap beberapa Indeks Sektoral seperti sektor Consumer, Finance, Manufacture, Mining, Misc Industry dan Property. Variabel indenpenden Inflasi AS menunjukkan bahwa Inflasi AS tidak berpengaruh signifikan terhadap Indeks Sektoral di Indonesia kecuali sektor Mining saja. Variabel indenpenden Kurs Rupiah menunjukkan bahwa Kurs rupiah hanya kurang berpengaruh signifikan terhadap sebagian 
Indeks Sektoral di Indonesia yaitu antara lain sektor Consumer, Mining, Property dan Trade.

\subsection{Uji F}

Seluruh data penelitian untuk seluruh sektor sudah signifikan.

\subsection{Koefisien Determinasi $\left(R^{2}\right)$}

Variabel indenpenden mampu menjelaskan sektor Agriculture sebesar 81,3\%, sektor Basic Industry sebesar $81,2 \%$, sektor Consumer sebesar $86 \%$, sektor Finance sebesar 69,9\%, sektor Infrastructure sebesar 66,7\%, sektor Manufacture sebesar 80,3\%, sektor Mining sebesar 87,2\%, sektor Misc Industry sebesar 76,2\%, sektor Property sebesar $86,4 \%$ dan sektor trade sebesar $21,3 \%$.

\section{KESIMPULAN DAN SARAN}

\subsection{Kesimpulan}

Berdasarkan hasil penelitian yang telah dilakukan dapat disimpulkan: Model regresi layak karena telah memenuhi uji asumsi klasik. Berdasarkan hasil pengujian H1, Dow Jones Index memiliki pengaruh yang cukup tinggi dalam penelitian. Berdasarkan hasil pengujian $\mathrm{H} 2$, Suku bunga efektif AS tidak memiliki pengaruh yang signifikan dalam penelitian. Berdasarkan hasil pengujian H3, Harga Emas hanya memiliki pengaruh terhadap sebagian sektor dalam penelitian. Berdasarkan hasil pengujian H4, Harga Minyak Bumi hanya memiliki pengaruh terhadap sebagian sektor dalam penelitian. Berdasarkan hasil pengujian H5, Inflasi AS memiliki signifikansi yang rendah dalam penelitian. Berdasarkan hasil pengujian H6, Kurs Rupiah hanya memiliki signifikansi terhadap sebagian sektor dalam penelitian. Berdasarkan hasil Uji F, dapat disimpulkan bahwa secara keseluruhan data memiliki signifikansi terhadap Indeks Sektoral.

\subsection{Keterbatasan}

Data-data Variabel penelitian ini lebih mencerminkan kondisi makro berdasarkan kondisi ekonomi international dan data-data ini dipilih untuk mengetahui pengaruh kondisi makro terhadap masing-masing Indeks Sektoral di Indonesia. Tahun amatan terbatas pada tahun 2014-2016 sesuai data yang diambil untuk penelitian. Tidak dipertimbangkannya data ekonomi negara Indonesia lainnya.

\subsection{Saran}

Untuk mengatasi keterbatasan penelitian ini, penelitian kedepan perlu menambahkan variabel indenpenden. Bagi investor dan trader, disarankan untuk memeriksa fundamental perusahaan sebelum melakukan investasi kedepan.

\section{DAFTAR PUSTAKA}

Buku

Ghozali, Imam. (2011). Aplikasi Analisis Multivariate dengan Program IBM SPSS 19 Cetakan V. Semarang: Badan Penerbit Universitas Diponegoro.

Canada,Sullivan; and White. 1996. "Capital Investment Analysis For Engineering and Management, $2^{\text {nd }}$ Edition”. United States: Pearson Prentice Hall.

Khrystenko, Sergey. 2007. "The Dow Jones Index for Intellectual Sphere". NewYork:New York Times.

Nugrahanti, Asri. 2011. Harga Minyak Bumi, Harga BBM, dan Peranan Pemerintah. Jakarta: Universitas Trisakti.

Maloney, Michael. 2011. Guide to Investing in Gold and Silver: Protect Your Financial Future. NewYork: Business Plus.

Indonesia Stock Exchange. 2010. Buku Panduan Indeks Harga Saham Bursa Efek Indonesia. Jakarta: Indonesia Stock Exchange.

Siamat,D. (2001). Management Lembaga Keuangan Edisi Ketiga. Jakarta: Fakultas Ekonomi Universitas Indonesia.

Boediono. 2001. Ekonomi Makro Edisi 4. Yogyakarta: BPFE. 
Fabozzi, Franco. 1996. Capital Markets: Institution and Intruments $2^{\text {nd }}$ Edition. United States: Pearson Prentice Hall.

Block, Stanley B; Hirt, Geoffrey A. 1993. Foundations Of Financial Management. United States: Irwin Professional Publishing.

Thesis

Calvina. 2014. Pengaruh Komoditi Minyak, Emas dan Nilai Tukar Riil terhadap Indeks Harga Saham Gabungan di Bursa Efek Indonesia periode 2009 sampai dengan 2013. Thesis Pasca Sarjana Universitas Tarumanagara.

Hartono, Gery. 2014. Analisis Pengaruh Inflasi, Suku Bunga BI, Nilai Tukar dan Pertumbuhan PDB terhadap Harga Saham Perusahaan Sektor Barang Konsumsi yang Terdaftar di Bursa Efek Indonesia. Thesis Pasca Sarjana Universitas Tarumanagara.

Kristianingrum, Felicia. 2014. Analisis Pengaruh Inflasi, Suku Bunga SBI dan Nilai Tukar Rupiah /Dollar Terhadap Nilai Indeks Saham LQ45 Tahun 2009 - 2013. Thesis Pasca Sarjana Universitas Tarumanagara.

Jurnal

Susanto, Budi. 2013. Analisis Pengaruh Ekonomi Makro, Indeks Dow Jones dan Indeks Nikkei 225 terhadap Indeks Harga Saham Gabungan (IHSG) di BEI Periode 2007 - 2011. Jurnal Ilmiah Mahasiswa Universitas Surabaya.

Michelia. 2014. Pengaruh Tingkat Inflasi, Suku Bunga SBI dan Nilai Tukar Rupiah (IDR/USD) Terhadap Indeks LQ45 di Bursa Efek Indonesia (BEI) periode 2006 2012. Thesis Pasca Sarjana Universitas Tarumanagara.

Hirman. 2014. Analisis Pengaruh Tingkat Inflasi, Suku Bunga SBI dan Nilai Tukar Rupiah Dollar AS Terhadap Return Saham Perbankan yang Terdaftar Pada Kelompok LQ45. Thesis Pasca Sarjana Universitas Tarumanagara.

Joetiar, Silvany. 2013. Analisis Pengaruh Inflasi, Kurs Dollar Amerika Serikat, Harga Emas Antam dan Suku Bunga terhadap Harga Saham Indeks LQ45. Thesis Pasca Sarjana Universitas Tarumanagara.

Sugiarto, Harry. 2014. Analisa Pengaruh Tingkat Inflasi, Nilai Tukar Rupiah, Tingkat Suku Bunga SBI, Harga Emas Dunia, Harga Minyak Dunia dan Indeks Dow Jones Terhadap Pergerakkan Indeks Harga Saham Gabungan (IHSG) di Bursa Efek Indonesia Periode Januari 2009 - September 2014. Thesis Pasca Sarjana Universitas Tarumanagara.

Hermandy. 2014. Pengaruh Perubahan harga Emas, Suku Bunga, Tingkat Inflasi dan Nilai Tukar USD Terhadap Pergerakkan Indeks Harga Saham gabungan Periode januari 2005 - Desember 2011. Thesis Pasca Sarjana Universitas Tarumanagara.

Sari, Anisya. 2014. Pengaruh Tingkat Inflasi, Suku Bunga SBI dan Nilai Tukar Rupiah Pada US Dollar Terhadap Pergerakkan Indeks harga Saham Gabungan Perusahaan Manufaktur yang Terdaftar Pada Bursa Efek Indonesia Periode Tahun 2010 - 2013. Fakultas Ekonomi Universitas Dian Nuswantoro Semarang.

Arifin, Tri. 2014. Pengaruh Inflasi, Suku Bunga SBI, Perubahan Kurs dan Standard \& Poor's 500 Terhadap Indeks harga Saham Gabungan (IHSG). Universitas Negeri Yogyakarta.

Budiantara. 2012. Pengaruh Tingkat Suku Bunga, Nilai Kurs, dan Inflasi Terhadap Indeks Harga Saham Gabungan Di Bursa Efek Indonesia Periode Tahun 2005 - 2010. Universitas Mercu Buana Yogyakarta.

Hasiholan, Samuel. 2012. Analisis Pengaruh Inflasi, Kurs Valuta Asing dan Suku Bunga Terhadap Indeks LQ45.Universitas Gunadarma Jakarta.

Laila, Hilya., Darminta., Hidayat R. 2014. Pengaruh Tingkat Suku Bunga, Tingkat Inflasi, Nilai Kurs Dollar dan Indeks Strait Times terhadap Indeks Harga Saham Gabungan. Universitas Brawijaya Malang. 
Novita, Nora. 2011. Pengaruh Volume Perdagangan, Suku Bunga, dan Kurs Terhadap LQ45 beserta Prediksi Indeks LQ45. Universitas Diponegoro Semarang.

Ernayani, Rihfenti., Mursalin Adi. 2015. Pengaruh Kurs Dolar, Indeks Dow Jones dan Tingkat Suku Bunga SBI terhadap IHSG. Universitas Negeri Padang.

Krisna, Aditya., Wirawati, Putu. 2012. Pengaruh Inflasi, Nilai Tukar Rupiah, Suku Bunga SBI Pada Indeks Harga Saham Gabungan di BEI. Universitas Udayana Bali. Masodah., Riskayanto., Herawati, Septi. 2013. Analisis Pengaruh Tingkat Inflasi, Harga minyak Dunia, harga Emas Dunia, dan Kurs Rupiah Terhadap pergerakkan Jakarta Islamic Index di Bursa Efek Indonesia. Universitas Gunadarma.

Rohman, Jahad. 2015. Pengaruh Inflasi, Kurs Rupiah terhadap Dollar dan BI Rate terhadap Indeks Saham Syariah Jakarta Islamic Index di Bursa Efek Indonesia. Universitas Muhammadiyah Surakarta.

Hismendi., Hamzah Abubakar., Musnadi Said. 2013. Analisis Pengaruh Nilai Tukar, SBI, Inflasi dan Pertumbuhan GDP terhadap Pergerakkan Indeks Harga Saham Gabungan di Bursa Efek Indonesia. Universitas Syiah Kuala banda Aceh.

Muradoglu,Gulnur; Taskin,Fatma; dan Bigan, Iika.2000."Causality Between Stock Returns and Macroeconomic Variables In Emerging Markets." Russian \& East Europe Finance and Trade 36(6):33-53

Oskenbayev,Yessengali; Yilmaz, Mesut; dan Chagirov, Pauren. 2011. "The Impact Of Macroeconomic Indicators On Stock Exchange Performance In Kazakhstan”.African Journal Of Business management 5(7):2985-2991

Ayaji, R.A - Mougoue, M. 1996. On The Dynamic Relation Between Stock Prices and Exchange Rates. Journal Of Financial Research, vol 19, 1996, 193-207.

Website

https://jimmyrahdiansyah.wordpress.com/2010/10/06/suku-bunga-interest-rate/ diakses pada tanggal 27 April 2017

https://www.investing.com diakses pada tanggal 24 April 2017

http://www.idx.co.id/ diakses pada tanggal 24 April 2017

http://www.investopedia.com/ diakses pada tanggal 24 April 2017 
